\title{
INDUÇÃO DA FRUTIFICAÇÃO PATERNOCÁRPICA DE FRUTOS EM HÍBRIDO DE ABÓBORA JAPONESA COM 2,4-D SOB CONDIÇÕES DE TEMPERATURA ELEVADA
}

\author{
FERREIRA, Tiago Alves ${ }^{1}$ \\ OLIVEIRA, Cleuton Ribeiro de ${ }^{2}$ \\ CHAVES, Prínscilla Pamela Nunes ${ }^{3}$ \\ MILHOMENS, Kellen Kiara Barros ${ }^{4}$ \\ BARROS, Helio Bandeira ${ }^{5}$ \\ NASCIMENTO, Ildon Rodrigues do ${ }^{5}$
}

\begin{abstract}
RESUMO: O objetivo do trabalho foi avaliar o efeito de doses de 2,4-D (ácido 2,4-diclorofenoxiacético) na produção de frutos de abóbora japonesa em Gurupi - TO. O delineamento experimental utilizado foi de blocos casualizados com oito tratamentos e quatro repetições. Foram testadas sete doses do regulador vegetal em baixa concentração aplicado na forma de 2,4-D, nas seguintes concentrações 187,$5 ; 200 ; 212,5 ; 225 ; 237,5 ; 250$ e 262,5 mg. $\mathrm{L}^{-1}$ e mais a testemunha (polinização com pólen) feita de forma manual. Avaliou-se peso médio de fruto, produtividade média de frutos, formato de fruto e textura da casca. Os dados foram submetidos à análise de variância e ajustado equações de regressão. $\mathrm{O}$ tratamento com pólen foi comparado aos demais por contraste. $\mathrm{O}$ uso de 2,4-D promoveu uma boa taxa de frutificação, com produtividade média de 24,35 ton ha ${ }^{-1}$, não diferindo estatisticamente da testemunha, pelo teste de Dunnett. O uso de 2,4D na dose 225,0 mg.L-1 resultou em aumento no peso médio dos frutos colhidos. Não houve incremento de produtividade, de acordo com as diferentes concentrações de 2,4D, e o formato e espessura da casca não foram alterados.
\end{abstract}

Palavras-chave: Cucurbita máxima x Cucurbita moschata. Partenocarpia. Auxinas. Produtividade.

SUMMARY: The objective of this work was to evaluate the effect of doses of 2,4-D (2,4-dichlorophenoxyacetic acid) on the production of Japanese pumpkin fruits in Gurupi-TO. The experimental design was a randomized block with eight treatments and four replications. Seven doses of the plant regulator in low concentration applied in the form of 2,4-D were tested in the following concentrations $187.5 ; 200 ; 212.5 ; 225 ; 237.5 ; 250$ and $262.5 \mathrm{mg} . \mathrm{L}^{-1}$ plus the control (pollination with pollen) made manually. Average fruit weight, average fruit yield, fruit shape and bark texture were evaluated. Data were submitted to analysis of variance and adjusted regression equations. The treatment with pollen was compared to the others by contrast. The use of 2,4-D promoted a good fruiting rate, with an average yield of 24.35 tons ha ${ }^{-1}$, not statistically different from the control by the Dunnett test. The use of 2,4 D in the 225.0 mg. $\mathrm{L}^{-1}$ dose resulted in an increase in the average weight of the fruits harvested. There was no increase in productivity, according to the different concentrations of $2,4 \mathrm{D}$, and the shape and thickness of the bark were not altered.

Keywords: Cucurbita máxima x Cucurbita moschata. Parthenogenesis. Auxins. Yield.

\section{INTRODUÇÃO}

As cucurbitáceas ocupam lugar de destaque no Brasil (FILGUEIRA 2003). Dentre estas, a cultura da abóbora tem grande importância social e econômica, pois é consumida por todas as classes sociais, sendo excelente fonte de açúcares, fibras e carboidratos, além de ser rica em carotenóides como $\alpha$ caroteno, $\beta$-caroteno e luteína (VERONEZI;JORGE 2011).

\footnotetext{
${ }^{1}$ Doutorando em Produção Vegetal pela Universidade Federal do Tocantins

${ }^{2}$ Mestre em Produção Vegetal, pela Universidade Federal do Tocantins.

${ }^{3}$ Doutoranda em Horticultura - Universidade Estadual de São Paulo "Julio de Mesquita Filho" - UNESP - Botucatu.

${ }^{4}$ Doutoranda em Produção Vegetal pela Universidade Federal do Tocantins

${ }^{5}$ Professor Doutor da Universidade Federal do Tocantins.
} 
O principal centro de diversidade da abóbora é o continente americano, mais precisamente a área central do México. São plantas de clima quente, com temperaturas ótimas para o desenvolvimento e frutificação variando de $20^{\circ}$ à $27^{\circ} \mathrm{C}$. O Estado do Tocantins apresenta clima favorável para o cultivo de abóboras, podendo ser cultivada o ano todo, caso haja disponibilidade de irrigação nos períodos secos.

No Brasil, tem se utilizado uma grande variedade de tipos de abóboras, morangas que diferem no formato, tamanho, cor da casca, cor da polpa, firmeza, teor de amido, teor de matéria seca e capacidade de armazenamento e sabor (NASCIMENTO et al. 2008). O cultivo da abóbora é uma prática bastante realizada em diversos estados brasileiros e ultimamente o uso de híbridos interespecíficos, denominado de abóbora japonesa e/ou "Tetsukabuto", tem sido uma alternativa rentável aos produtores, quando comparada a exploração de abóboras comuns.

A abóbora japonesa é um híbrido interespecífico resultante do cruzamento entre linhagens selecionadas de abóboras das espécies (Cucurbita maxima) com linhagens da espécie (Cucurbita moschata), sendo a primeira empregada como genitor feminino, e a segunda como genitor masculino, respectivamente (BISOGNIN 2002). Este híbrido foi inicialmente desenvolvido por programas de melhoramento japonês (ROBINSON;DECKER-WALTERS 1997) e apresentaram boa adaptação ao cultivo em todas as regiões do Brasil (PEREIRA 1999). As abóboras do tipo "Tetsukabuto" ocupam o sétimo lugar dentre as hortaliças cultivadas no Brasil (NASCIMENTO et al. 2008), chegando a dominar o mercado em algumas regiões brasileiras (ISLA 2011).

A abóbora híbrida apresenta várias vantagens sobre as cultivares de polinização aberta, como: precocidade, resistência à broca, estabilidade de produção, uniformidade no tamanho e coloração do fruto, resistência ao manuseio, transporte e conservação pós-colheita, melhor qualidade nutritiva e culinária (VILELA et al. 2007).

A abóbora japonesa é uma planta monóica, entretanto as flores masculinas são estéreis havendo, assim, a necessidade de utilização no plantio de uma espécie de abóbora comum fornecedora de pólen (NASCIMENTO et al. 2008).

A produção de frutos na abóbora japonesa pode ser feita também por via sexuada ou assexuada. Por meio sexuada é necessário que haja o plantio de uma espécie fornecedora de pólen que ocupa aproximadamente $20 \%$ da área de plantio. Essa técnica é dependente da polinização realizada por insetos, principalmente abelhas (MINUSSI;ALVES 2007). Entretanto o rendimento e a qualidade dos frutos são acentuadamente reduzidos quando a polinização é deficiente (STANGHELLINI et al. 1998), podendo ocorrer reduções no rendimento de até $90 \%$ na ausência de abelhas polinizadoras (GILL 1989). Na produção assexuada adota-se o uso de regulador vegetal do grupo das auxinas, que, quando pulverizados na flor aberta, diretamente sobre o pistilo, asseguram a formação do fruto pelo processo denominado de partenocarpia, sem necessidade de polinização entomófila (PASQUALETTO et al.2001). O desenvolvimento normal de um bom número de frutos pode ser feito pelo uso correto de reguladores vegetais, eliminando a necessidade de plantio de cultivares polinizadoras, e ainda permite contornar os problemas relativos às condições climáticas, que podem comprometer a atividade de abelhas polinizadora (VILELA et al. 2007).

Estudos realizados por Amarante et al. (2000) e Pasqualetto et al. (2001) com abóbora e Godoy et al. (2004) com pepino, sobre a produção de frutos por partenocarpia com uso de 2,4-D, demonstram ser possível a obtenção de frutos com o uso de 2,4-D, porém a dose utilizada pode variar com as condições ambientais. Estudos sobre a produção de híbridos do com fruto tipo "Tetsukabuto" com produção via assexuada com uso de reguladores vegetal, indicando qual dose mais apropriada a essa cultura, pode ser uma alternativa aos produtores. Objetivou-se com esse trabalho avaliar o efeito de doses de 2,4-D (ácido 2,4-diclorofenoxiacético) na produção de frutos de abóbora japonesa. 


\section{MATERIAL E MÉTODO}

O experimento foi conduzido na área experimental da Universidade Federal do Tocantins Campus

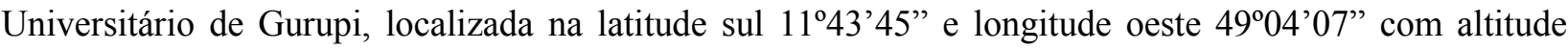
média de $280 \mathrm{~m}$. O clima da região é caracterizado por apresentar domínio climático tropical semi- úmido, com temperatura média anual variando de 26 a $27^{\circ} \mathrm{C}$. Com essas temperaturas e índices de pluviosidade, o clima recebe a classificação de AW - Tropical de verão úmido e período de estiagem no inverno, de acordo com a classificação de Köppen (1928).

O delineamento experimental utilizado foi em blocos casualizados (DBC), com sete tratamentos, sendo sete doses de 2,4-D (ácido 2,4-diclorofenoxiacético), nas concentrações de 187,5; 200; 212,5; 225; 237,5; 250 e 262,5 $\mathrm{mg} \mathrm{L}^{-1}$ mais a testemunha (polinização com pólen) feita de forma manual em quatro repetições. Cada parcela foi constituída por uma fileira composta por cinco plantas, espaçadas de 2,0 m entre linhas e 2,0 m entre plantas. Foram consideradas como parcela útil as três plantas centrais.

A semeadura foi realizada em covas de $0,2 \times 0,2 \times 0,2 \mathrm{~m}$, por meio de semeadura direta colocando-se duas sementes por cova da abóbora híbrida japonesa cultivar Kyoto. A adubação de base e de cobertura foi realizada segundo recomendação da cultura sugerida pela Comissão de Fertilidade do Solo do Estado de Minas Gerais (AVELAR, 1999), com base na análise de solo (Tabela 1). Após a semeadura as covas foram cobertas com palhada de soja num raio de $0,20 \mathrm{~m}$.

Tabela 1. Resultado da análise físico química do solo utilizado no experimento com abóbora híbrida japonesa Tetsukabuto, Gurupi- TO.

\begin{tabular}{|c|c|c|c|c|c|c|c|c|c|c|c|c|c|}
\hline$\left(\mathrm{H}_{2} \mathrm{O}\right)$ & $\left(\mathrm{g} / \mathrm{dm}^{3}\right.$ & \multicolumn{6}{|c|}{${ }_{\mathrm{C}} \mathrm{mol} / \mathrm{dm}^{3}$} & \multicolumn{2}{|c|}{$\mathrm{mg} / \mathrm{dm}^{3}$} & $(\%)$ & \multicolumn{3}{|c|}{ Textura $\left(\mathrm{g} / \mathrm{dm}^{3}\right)$} \\
\hline $\mathrm{pH}$ & M.O & $\mathrm{Ca}$ & $\mathrm{Mg}$ & $\mathrm{H}+\mathrm{Al}$ & $\mathrm{Al}$ & SB & $\begin{array}{l}\text { CT } \\
\text { C }\end{array}$ & $\mathrm{K}$ & $\begin{array}{l}\mathrm{P}(\mathrm{Mel} \\
\end{array}$ & $\mathrm{V}$ & Areia & Silte & $\begin{array}{l}\text { Argil } \\
\text { a }\end{array}$ \\
\hline 5,89 & 1,35 & $\begin{array}{l}1,9 \\
8\end{array}$ & $\begin{array}{l}1,3 \\
8\end{array}$ & 2,43 & $\begin{array}{l}0,0 \\
0\end{array}$ & $\begin{array}{l}3,4 \\
3\end{array}$ & 5,86 & $\begin{array}{l}34,9 \\
2\end{array}$ & 14,54 & 58,49 & 73,10 & $\begin{array}{l}4,0 \\
5\end{array}$ & $\begin{array}{l}22,8 \\
8\end{array}$ \\
\hline
\end{tabular}

As sementes foram tratadas com fungicida Carbendazim-Thiram 200 SC, na dosagem de $200 \mathrm{ml}$ $100 \mathrm{~kg}^{-1}$ de semente. Aos 13 dias após semeadura realizou-se desbaste deixando uma planta por cova. A deficiência hídrica foi suplementada com irrigação por aspersão.

O controle de pragas e doenças foi executado conforme necessário segundo recomendações de Puiatti e Derly, (2005). O controle de plantas daninhas foi realizado até os 25 dias após a semeadura por meio de capina manual.

No preparo da solução reguladora vegetal foi utilizado DMA $806 \quad$ BR $^{\circledR} \quad$ (2,4-D) Dimethylammonium (2,4-dichlorophenoxy) acetate (2,4-D, sal dimetilamina), $806 \mathrm{~g}$ ingrediente ativo por litro. Por diluição foram obtidas as seguintes concentrações: 187,5; 200; 212,5; 225; 237,5; 250 e 262,5 $\mathrm{mg}$. $\mathrm{L}^{-1}$ de 2,4-D.L $\mathrm{L}^{-1}$. Após o preparo da solução está foi guardada em lugar fresco e sombreado e renovada a cada semana.

Para frutificação partenocárpica foram realizadas pulverizações com pulverizador manual contendo $5 \mathrm{ml}$ de cada solução nas flores femininas abertas, porém protegidas, entre 6:00 e 9:00 horas da manhã. Após as pulverizações as flores foram novamente protegidas com sacos de papel para evitar polinização indesejável. O pólen da testemunha foi obtido de plantas da cultivar de abóbora Menina Brasileira plantada com 18 dias de antecedência em local distante do experimento. 
Foram colhidos frutos maduros de cada parcela, avaliando-se as seguintes características: peso médio de frutos: estimado à partir da pesagem dos frutos comerciais colhidos na parcela útil; produtividade de frutos: estimado à partir do somatório do peso dos frutos colhidos da área útil de cada parcela e o resultado foi convertido em ton $\mathrm{ha}^{-1}$; formato deosfrutos: estimado em quatro frutos por tratamento, segundo escala de notas, em que: 1 - frutos com formato globular; 2 - frutos com formato globular achatado; 3 - frutos esféricos, 4 - frutos com formato cilíndrico; e 5 - frutos alongados; textura da casca dos frutos - estimado em quatro frutos por tratamentos, por meio de escala de notas, em que: 1 fruto com textura da casca lisa; 2 - fruto com textura da casca finalmente ondulada; e 3 - fruto com textura da casca ondulada.

Os dados obtidos foram submetidos à análise de variância pelo teste F, para efeito de doses de 2,4$\mathrm{D}$ foram ajustados equações de regressão que melhor ajustasse aos valores observados . Foram estabelecidos contrastes de médias para comparar a média dos tratamentos (doses de 2,4-D) com a testemunha (frutos obtidos de polinização). Todas as análises foram feitas com programa estatístico Sisvar (FERREIRA, 2011).

\section{RESULTADO E DISCUSSÃO}

Comparando as doses de 2,4D com a testemunha (polinização manual) não foram detectadas diferenças significativas pelo teste de Dunnett, para todas as variáveis, exceto para a variável PMF na dose $225,0 \mathrm{mg} \mathrm{L}^{-1}$, onde foi observado frutos com maior peso médio (Tabela 2).

Tabela 2. Médias estimadas para peso médio de frutos (PMF em kg.planta ${ }^{-1}$ ), produtividade de frutos (PROD em ton.ha ${ }^{-1}$ ), formato do fruto (FORM) e textura da casca (TEXT) em frutos de abóbora híbrida japonesa em função de doses de 2,4 D Gurupi, TO. 2012.

\begin{tabular}{|c|c|c|c|c|c|c|c|c|c|c|}
\hline \multirow{2}{*}{$\begin{array}{l}\text { Caracte } \\
\text { rística }\end{array}$} & \multicolumn{7}{|c|}{ Doses 2,4-D (mg.L $\left.{ }^{-1}\right)$} & \multirow[b]{2}{*}{$\begin{array}{l}\text { Tes } \\
\text { t. }\end{array}$} & \multirow[b]{2}{*}{ Equações de regressão } & \multirow[b]{2}{*}{$\mathbf{R}^{2}$} \\
\hline & $\begin{array}{l}187, \\
5\end{array}$ & $\begin{array}{l}200, \\
0\end{array}$ & $\begin{array}{l}212, \\
5\end{array}$ & $\begin{array}{l}\text { 225, } \\
0\end{array}$ & $\begin{array}{l}237, \\
5\end{array}$ & $\begin{array}{l}250, \\
0\end{array}$ & $\begin{array}{l}262, \\
5\end{array}$ & & & \\
\hline PMF & 2,26 & 2,18 & 2,21 & $\begin{array}{l}2,29 \\
*\end{array}$ & 2,24 & 2,22 & 2,16 & $\begin{array}{l}2,0 \\
7\end{array}$ & $\begin{array}{c}Y=3,264 x^{2}+0,0146 x+ \\
0,2567\end{array}$ & 0,86 \\
\hline PROD & $\begin{array}{l}23,7 \\
4\end{array}$ & $\begin{array}{l}20,9 \\
9\end{array}$ & $\begin{array}{l}22,9 \\
6\end{array}$ & $\begin{array}{l}25,0 \\
5\end{array}$ & $\begin{array}{l}25,6 \\
7\end{array}$ & $\begin{array}{l}25,5 \\
5\end{array}$ & $\begin{array}{l}24,0 \\
6\end{array}$ & $\begin{array}{l}26 \\
78\end{array}$ & $Y=24,35$ & - \\
\hline FORM & 2,00 & 2,25 & 2,31 & 2,19 & 1,94 & 2,13 & 2,13 & $\begin{array}{l}2,1 \\
2\end{array}$ & $Y=2,25$ & - \\
\hline TEXT & 1,38 & 1,56 & 1,69 & 1,5 & 1,56 & 1,25 & 1,56 & $\begin{array}{l}1,3 \\
1 \\
\end{array}$ & $Y=1,66$ & - \\
\hline
\end{tabular}

* Médias diferentes da testemunha a 5\% de probabilidade pelo teste de Dunnett.

Para a característica peso médio de fruto houve diferença significava somente para a dose 225,0 $\mathrm{mg} \mathrm{L}^{-1}$ com média de 2,29 $\mathrm{Kg}$ por fruto sendo, portanto superior à testemunha que foi de 2,07 Kg. Para as demais doses, não houve diferença significativa, quando comparadas com a testemunha. Tais resultados assemelham-se aos encontrados por Amarante et al. 2000, que avaliou a frutificação e crescimento de frutos em abóbora híbrida japonesa.

Para peso médio de fruto, houve ajuste de equação de regressão quadrática em que observou o maior peso médio de frutos com 2,29 kg na dose de 225,0 mg.L $\mathrm{L}^{-1}$ (Figura 1). A partir deste valor houve tendência de redução no peso médio dos frutos, sendo observado o menor valor $(2,16 \mathrm{~kg})$ na maior 
concentração de 2,4-D (262,5 mg.L. $\left.\mathrm{L}^{-1}\right)$. Segundo Amaro et al. (2014), frutos de Tetsukabuto, tem o seu peso ideal de 2,0 á $3,0 \mathrm{~kg}$.

Figura 1. Peso médio de frutos em abóbora híbrida japonesa em função de doses de 2,4-D. Gurupi, TO. 2011.

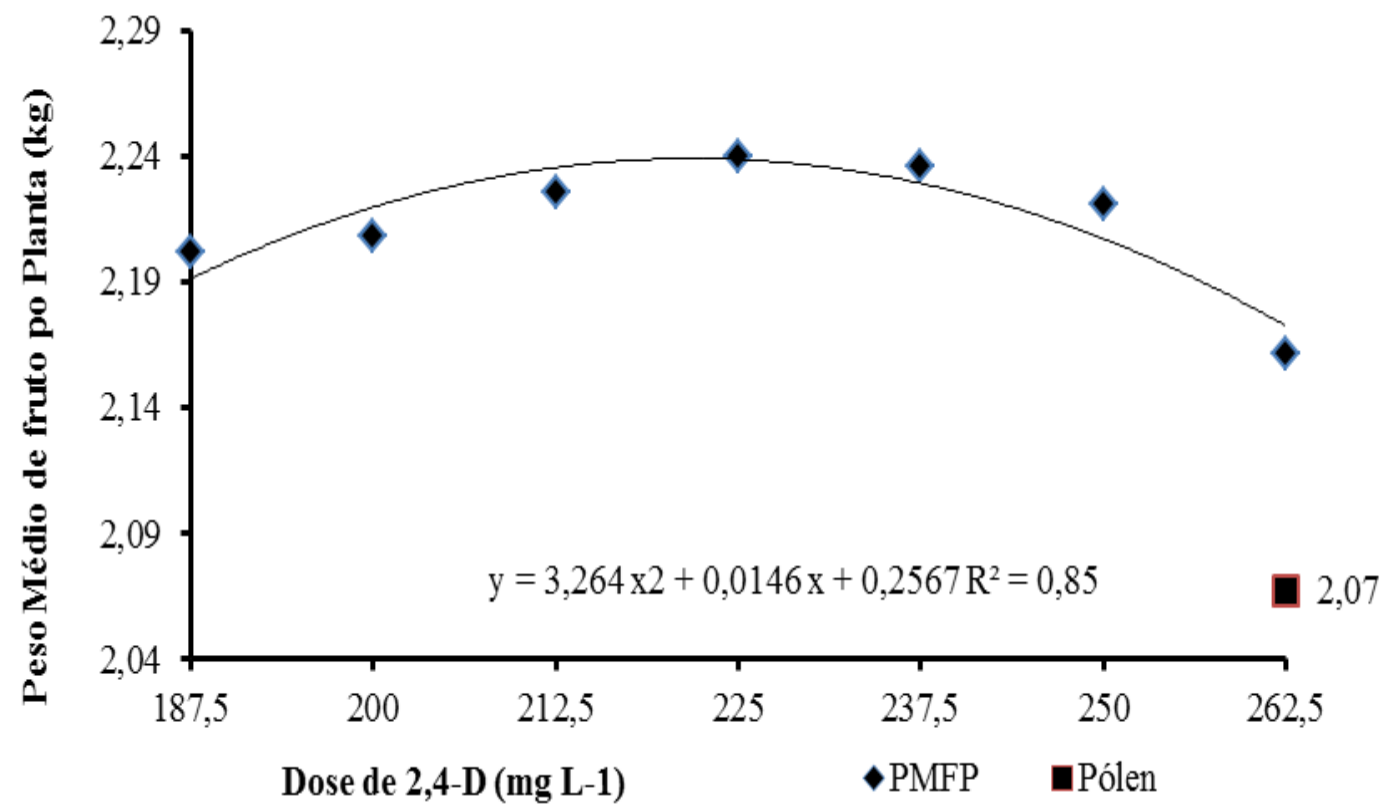

Para produtividade de frutos não foi observado diferença significativa dos tratamentos com aplicação de doses de 2,4-D e a testemunha, em que obteve-se produtividade média de 26,78 ton ha ${ }^{-1}$. Porém as doses utilizadas apresentaram produtividade acima da média nacional. Amarante et al (2000), afirma que as doses de utilização do 2,4D com efeito de regulador vegetal variam de 200 a $333 \mathrm{mg} . \mathrm{L}^{-1}$, as doses utilizadas nesse estudo variaram de acordo com a recomendação, e assim não acarretando em dados para a cultura. $\mathrm{O}$ formato do fruto variou de globular à globular achatada, característica padrão da abóbora hibrida japonesa. Visualmente, a textura da casca dos frutos foi alterada, sendo observado uma ligeira tendência de aumentar a rugosidade dos frutos quando se aumentou as doses de 2,4-D. Entretanto, quando comparado com o tratamento obtido à partir da polinização, não houve diferenças estatística (Tabela 2) com as diferentes concentrações de 2,4D utilizadas, porem não houve diferença estatística em relação as diferentes concentrações. Em comparação com os frutos obtidos de polinização manual, a casca do fruto tende em ser mais ondulada, conforme se alterou a concentração de 2,4D (Tabela 1). Miranda (2011), afirma que os frutos de abobora híbrida ideal para comercialização deve apresentar casca com textura um pouco rugosa e goma suave, indo ao de encontro com o tipo de casca que foi observado nós frutos de Tetsukabuto desse trabalho.

O uso de 2,4D quando comparado à polinização manual com pólen pode dispensar o cultivo de uma espécie polinizadora, resultando em aumento no peso médio dos frutos colhidos, conforme resultados de Franco (1999), o emprego dessa técnica pode promover incrementos significativos na produtividade de frutos. 


\section{CONCLUSÃO}

O uso de 2,4D na dose 225,0 mg. $\mathrm{L}^{-1}$ resultou em aumento no peso médio dos frutos colhidos.

Não houve incremento de produtividade, de acordo com as diferentes concentrações de $2,4 \mathrm{D}$, e o formato e espessura da casca não foram alterados.

\section{REFERÊNCIAS}

AMARO, G. B. et al. . Recomendações técnicas para o cultivo de abóbora híbrida do tipo japonesa. Brasília - DF: Embrapa Hortaliças, 2014 (Circular Técnica 137).

AMARANTE, C.V.T.; MACEDO, A.F.; ARRUDA, A.E. Frutificação e crescimento de frutos em abóbora híbrida 'Tetsukabuto' tratada com alfa-naftalenoacetato de sódio. Horticultura Brasileira, Brasília, v.18, n.3, p.212-214, 2000.

AVELAR FILHO, J.A, MELO, A. M. T. FILGUEIRA, F.A.R. Sugestões de adubação para hortaliças. In: RIBEIRO, C.A, GUIMARAÕES, P.T.G, V,V.H.A. Recomendações para o uso de corretivos e fertilizantes em Minas Gerais (5' Aproximação) - CFSEMG. Viçosa-1999, 175 e 176.

BISOGNIN, D.A. Origin and evolution of cultivated cucurbits. Ciência Rural, v. 32, p. 715- 723. 2002.

FERREIRA, D. F. Sisvar: a computer statistical analysis system. Ciência e Agrotecnologia (UFLA), v. 35, n.6, p. 1039-1042, 2011.

FILGUEIRA, F.A.R. Novo manual de olericultura: agrotecnologia moderna na produção e comercialização de hortaliças. 2. ed. Viçosa: UFV, p. 412, 2003.

FRANCO, M. 1999. Abóboras: fitohormônio aumenta a produção. Suplemento do Campo do Jornal de Brasília. Ano 12, n. 594.

GILL, R.A. The value of pollination services in Australia. Australasian Beekeeper, v. 91, n. 5, p. 256$275,1989$.

GODOY, A.R.; CARDOSO, A.I.I. Pegamento de frutos em pepino caipira não partenocárpio sob cultivo protegido com aplicação de ácido naftaleno acético. Bragantia, v.63, n.1, p. 25-29, 2004.

ISLA PAK. A super semente. Disponível em: http://www.isla.com.br/index.cgi Acesso em: 08 novembro. 2015.

KÖPPEN, W.; GEIGER, R. Klimate der Erde. Gotha: Verlag Justus Perthes. 1928.

MINUSSI, L. C.; ALVES, I. S. Abelhas nativas versus Apis mellifera Linnaeus, espécie exótica, (Hymenoptera: Apidae). Bioscience Journal, Uberlândia, v. 23, n. 1, p. 58-62, 2007.

MIRANDA, F.F.R. Efeito da frutificação induzida por 2,4-d em características agronômicas dos frutos de abóbora 'Tetsukabuto'. 2011. 62 f. Dissertação (Mestrado), Universidade Federal do Tocantins, Gurupi, Tocantins.

NASCIMENTO, W.M. et al.Eficiência de acessos de Cucurbita maxima como polinizadores de abóbora híbrida do tipo "Tetsukabuto". Horticultura Brasileira, v. 26, p. 540-542, 2008. 
PASQUALETTO, A.et al.Produção de frutos de abóbora híbrida pela aplicação de 2,4-D nas flores. Pesquisa Agropecuária Tropical, v.31, p.23-27, 2001.

PEREIRA, W. Recomendações para a frutificação da abóbora híbrida tipo Tetsukabuto: Uso de polinizadores e reguladores de crescimento de plantas. Brasília: Embrapa Hortaliças. 7p. (Embrapa Hortaliças. Comunicado Técnico, 12).1999

PUIATTI, M.S; DERLY, J.H. Abóboras e Morangas. In. Fontes, Paulo C.R. (Ed.). Olericultura: Teoria e Prática. Viçosa, UFV, p. 281-297, 2005.

ROBINSON, R.W; DECKER-WALTERS, D.S. Cucurbits. CAB International (Crop Production Science in Horticulture $n^{\circ}$ 6), New York, 226p, 1997.

SILVA, N.F.et al. Produção de abóbora híbrida em função de doses de fertilizante fórmula 4-14-8.

Ciência e Agrotecnologia, v. 23, p. 454-461, 1999.

STANGHELLINI, M.S.; AMBROSE, J.T.; SCHULTHEIS, J.R. Using commercial bumble bee colonies as backup pollinators for honey bees to produce cucumbers and watermelons. HortTechnology, v. 8, n. 4, p.590-594, 1998.

VERONEZI, C., JORGE, N.. CAROTENOIDES EM ABÓBORAS. Boletim do Centro de Pesquisa de Processamento de Alimentos, América do Norte, 29, ago. 2011. Disponível em: http://ojs.c3sl.ufpr.br/ojs2/index.php/alimentos/article/view/22734/16744. Acesso em: 10 Jan. 2015.

VILELA, N.J; GUIDUECI FILHO, E, ALMEIDA, V. E. S. Avaliação de Impactos Econômicos, Sociais e Ambientais - Frutificação sexuada e assexuada da abóbora híbrida. Brasilia- DF: Embrapa hortaliças. p. 17, 2007. 
